23

\title{
Лидарное зондирование смеси молекул сероводорода и метана в атмосфере с летающей платформы
}

\author{
(C) В.Е. Привалов ${ }^{1}$, В.Г. Шеманин ${ }^{1,2}$ \\ ${ }^{1}$ Санкт-Петербургский политехнический университет Петра Великого, \\ 194021 Санкт-Петербург, Россия \\ ${ }^{2}$ Новороссийский политехнический институт (филиал) Кубанского государственного технологического университета, \\ 353900 Новороссийск, Россия \\ e-mail: vaevpriv@yandex.ru
}

Поступила в редакцию 19.04.2019 г.

В окончательной редакции 12.07.2019 г.

Принята к публикации 09.09.2019 г.

Представлены результаты численного решения лидарного уравнения для комбинационного рассеяния света молекулами газовой смеси сероводорода и метана в направлении $180^{\circ}$ при зондировании молекул сероводорода и метана в атмосферном пограничном слое с концентрациями в диапазоне $10^{10}-10^{16} \mathrm{~cm}^{-3} \mathrm{c}$ летающей платформы на высотах до $500 \mathrm{~m}$ в режиме синхронного счета фотонов. Показано, что за время измерения $10 \mathrm{~s}$ при зондировании на длине волны лазерного излучения $405 \mathrm{~nm}$ и высоты полета платформы в диапазоне до $500 \mathrm{~m}$ может быть зарегистрирована концентрация исследуемых молекул сероводорода и метана ниже уровня ПДК для такого варианта лидара комбинационного рассеяния света.

Ключевые слова: лидар, уравнение, комбинационное рассеяние света, молекула, сероводород, метан, концентрация, летающая платформа, счет фотонов.

DOI: $10.21883 /$ OS.2019.12.48707.153-19

В Черном море существует обширный слой жидкого сероводорода $[1,2]$, который расположен на разных глубинах от 90 до $150 \mathrm{~m}$ в разных частях моря. Уровень сероводородного слоя постоянно пульсирует, поднимается иногда до уровня $75 \mathrm{~m}$, потом снижается. Поэтому возможно повышение концентрации молекул сероводорода и загрязнение ими атмосферного воздуха над морем. Параллельно с этим процессом идет эмиссия метана со дна [3]. Все это представляет серьезную проблему в связи с высокой токсичностью и взрывоопасностью этих газов.

Поэтому становится актуальной задача разработки новых вариантов лидаров для измерения концентрации молекул $\mathrm{H}_{2} \mathrm{~S}$ и $\mathrm{CH}_{4}$ на уровне от предельно допустимых концентраций (ПДК) до тысяч ПДК в атмосферном воздухе. Для сероводорода это значение ПДК всего $0.008 \mathrm{mg} / \mathrm{m}^{3}$ или порядка $1.4 \cdot 10^{11} \mathrm{~cm}^{-3}$, а ПДК метана $-200.0 \mathrm{mg} / \mathrm{m}^{3}$ или $7.6 \cdot 10^{15} \mathrm{~cm}^{-3}$ [4].

Ранее в [4-6] было отмечено, что лидар комбинационного рассеяния света может использоваться для дистанционного измерения концентрации молекул на уровне сотен и тысяч ПДК. А мониторинг газовых молекул с беспилотной летающей платформы может стать эффективным способом решения этой проблемы за счет большой площади охвата на поверхности моря или большого измерительного объема в атмосферном пограничном слое [5] для обнаружения молекул сероводорода и метана на уровне концентрации порядка ПДК и выше с летающей платформы в диапазоне высот до $500 \mathrm{~m}$.
Поэтому целью настоящей работы является оценка параметров лидара комбинационного рассеяния света для зондирования смеси молекул метана и сероводорода в атмосферном пограничном слое на уровне ПДК и выше с летающей платформы на высотах порядка сотен метров в режиме синхронного счета фотонов.

Для этого было выполнено компьютерное моделирование спектра комбинационного рассеяния света молекулами сероводорода и метана, предложен вариант лидара для решения такой задачи и численно решено лидарное уравнение для комбинационного рассеяния света молекулами метана и сероводорода в направлении $180^{\circ}$ для выбора длины волны лазерного излучения, параметров лидара и получения минимального значения концентрации исследуемых молекул на заданном расстоянии зондирования.

Значения максимумов и полуширин полос валентных $\mathrm{SH}$-колебаний молекул $\mathrm{H}_{2} \mathrm{~S}$ и симметричных валентных $\mathrm{CH}$-колебаний молекул $\mathrm{CH}_{4}$ взяты из $[3,7]$ и равны соответственно 2611, 2914, $3017 \mathrm{~cm}^{-1}$. Значения полуширин этих полос рассчитаны как в [9] и равны соответственно $0.033,0.054$ и $0.056 \mathrm{~cm}^{-1}$. Коэффициенты ослабления излучения в атмосфере для этих длин волн $\alpha\left(\lambda_{0}, z\right)$ и $\alpha(\lambda, z)$ и величины дифференциальных сечений колебательного комбинационного рассеяния света из $[4,8]$ собраны в таблице. Для нашей экспериментальной ситуации возьмем время измерения $10 \mathrm{~s}$. Поперечное сечение зеркала приемного телескопа лидара $-0.13 \mathrm{~m}^{2}$, а шаг по расстоянию $-7.5 \mathrm{~m}$. 


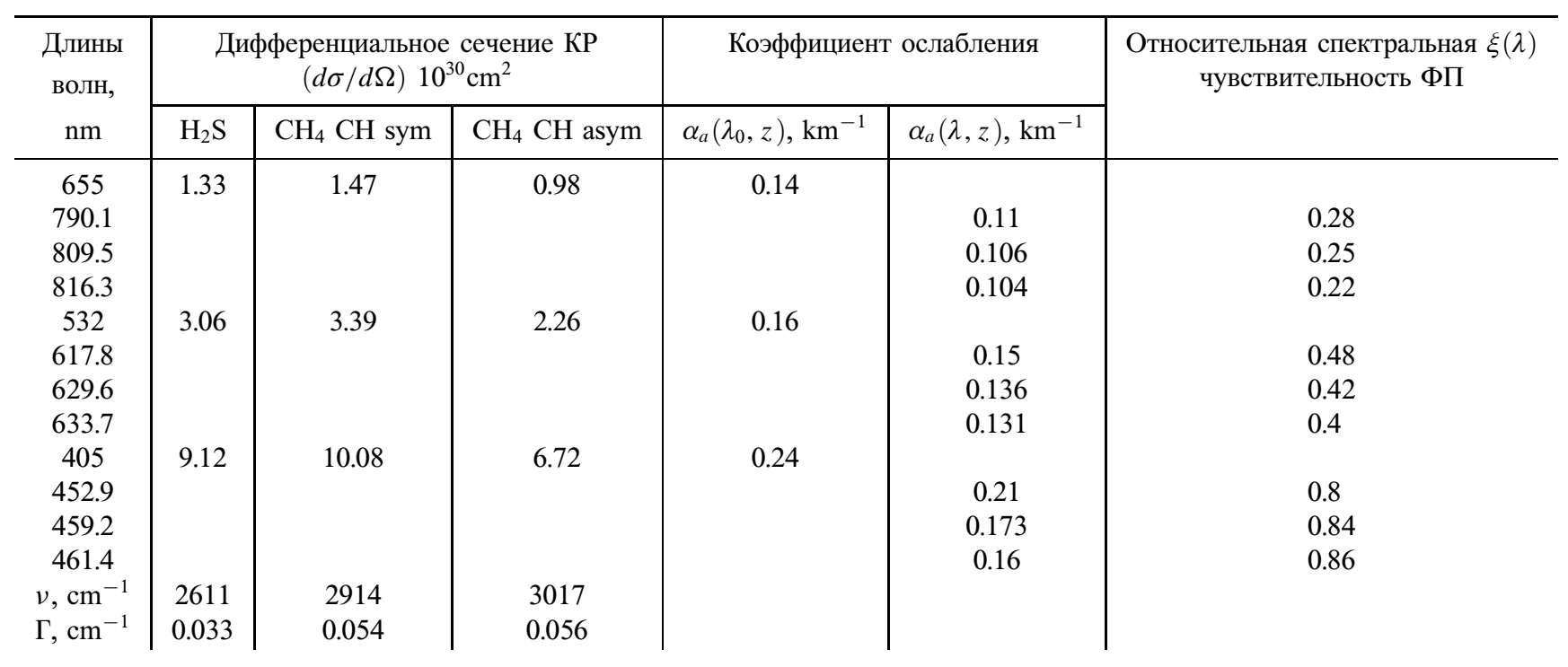

Длины волн лазерного излучения и полос КРС молекул сероводорода и метана, дифференциальные сечения колебательного комбинационного рассеяния света для этих полос, коэффициенты ослабления в атмосфере на этих длинах волн и относительная спектральная чувствительность фотоприемника.

На первом этапе по этим данным была выполнена компьютерная реконструкция спектра комбинационного рассеяния света молекулами газовой смеси в предположении, что концентрации исследуемых молекул равны 1 ПДК и полосы хорошо описываются функцией Гаусса [4] в виде

$$
A(v, H)=C N(H)\left(\frac{d \sigma}{d \Omega}\right) 1 / \Gamma \exp \left[-\left(v-v_{0}\right)^{2} / 2 \pi \Gamma^{2}\right],
$$

в котором $A(v, H)$ - интенсивность полосы комбинационного рассеяния света в относительных единицах, $v$ - волновое число, $v_{0}-$ волновое число в максимуме полосы, Г - полуширина полосы, $C$ констана, $N(H)$ - концентрация исследуемых молекул и $(d \sigma / d \Omega)$ - дифференциальное сечение комбинационного рассеяния света исследуемыми молекулами. Для того чтобы представить все три полосы комбинационного рассеяния света молекулами газовой смеси на одном графике, пришлось взять концентрацию сероводорода $10^{4}$ ПДК, так как эта величина на 4 порядка меньше уровня ПДК для метана [4]. Это видно на рис. 1.

Для регистрации такого спектра рассмотрим оптическую схему варианта лидара из $[1,4]$, приведенную на рис. 2.

Для зондирования молекул метана в атмосферном пограничном слое на уровне ПДК и выше достаточно регистрировать только одну полосу комбинационного рассеяния света и как более интенсивная была выбрана полома симметричного валентного СН-колебания с волновым числом $2914 \mathrm{~cm}^{-1}$. В качестве возможных

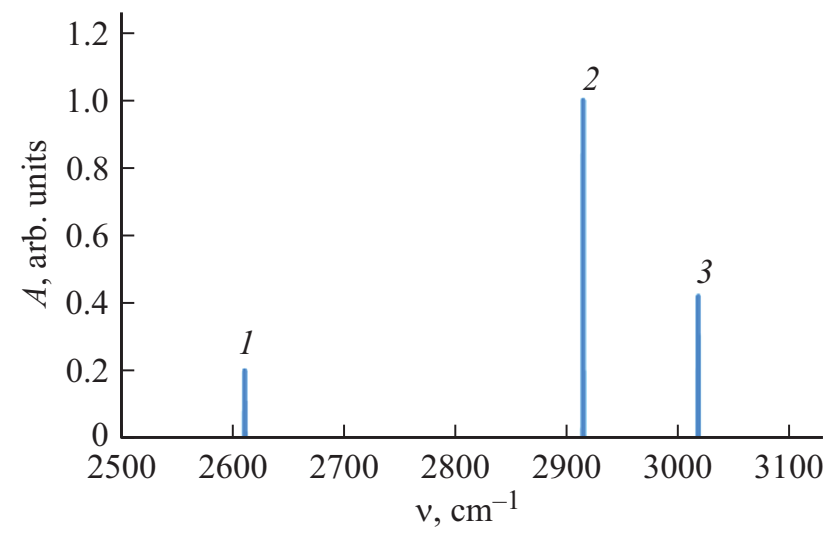

Рис. 1. График реконструированного спектра комбинационного рассеяния света газовой смеси сероводорода с концентрацией $10^{4}$ ПДК и метана-1 ПДК (полосы валентного SHколебания (1), симметричного валентного СН-колебания (2) и антисимметричного валентного СН-колебания (3)) с соответствующими значениями полуширин этих полос Г и дифференциальных сечений комбинационного рассеяния света $(d \sigma / d \Omega)$ из таблицы.

вариантов рассмотрим использование второй гармоники YAG:Nd-лазера (длина волны $532 \mathrm{~nm}$ ) с накачкой полупроводниковым лазером и полупроводниковых лазеров с длинами волн 405 и $655 \mathrm{~nm}$ с длительностью импульсов $10 \mathrm{~ns}$ и энергиями в импульсе до 100 мкДж при частоте следования лазерных импульсов $f$ до $1 \mathrm{Mgz}$ [4]. Малая мощность не представляла опасности для глаз. Излучение лазера 8 направлялось зеркалом 5 вдоль оси приемного телескопа, а излучение комбинационного рассеяния света молекулами сероводорода и метана в атмосферном пограничном слое в направлении назад собиралось приемным телескопом типа Ньютона со сферическим зеркалом 1 и фокусировалось линзовым объективом 9 на светоделитель 2, который направлял 
два луча каждый на свой интерференционный светофильтр 3 и фотоприемники 4, напряжения с которых $U_{1}$ и $U_{2}$ записывались в память микроконтроллера. Часть лазерного излучения направлялось стеклянной пластиной 5 через стеклянный светофильтр 7 на свой фотоприемник 4 , напряжение $U_{0}$ с которого также записывалось в память микроконтроллера для контроля энергии каждого лазерного импульса и формирования начала отсчета времени измерения или расстояния. В этом варианте лидара зондирование ведется только на двух длинах волн, соответствующих максимумам

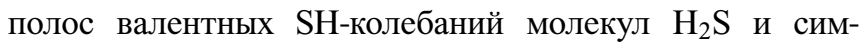
метричных валентных $\mathrm{CH}$-колебаний молекул $\mathrm{CH}_{4}$ из таблицы.

Лидарное уравнение для комбинационного рассеяния света исследуемыми молекулами в направлении назад в режиме счета фотонов запишем для чисел фотонов в виде [3]

$$
\begin{aligned}
n(\lambda, H)= & n_{0} K_{1} \Delta H G(H) f t_{d} S_{0} \exp \left[-\int_{0}^{H} \alpha\left(\lambda_{0}, z\right) d z\right. \\
& \left.-\int_{0}^{H} \alpha(\lambda, z) d z\right] N(H)\left(\frac{d \sigma}{d \Omega}\right) / H^{2},
\end{aligned}
$$

где $n(\lambda, H)$ - число фотонов, зарегистрированное фотодетектором лидара на длине волны комбинационного рассеяния света $\lambda$ с высоты $H ; n_{0}$ - число фотонов на длине волны лазерного излучения $\lambda_{0}, K_{1}$ - лидарная константа на длине волны $\lambda$, которая определялась как произведение спектрального пропускания приемного телескопа из [6] на величину относительной спектральной чувствительности фотоприемника $\xi(\lambda)$ [4] из таблицы, шаг по расстоянию $\Delta H=c \tau_{0} / 2=7.5 \mathrm{~m}, S_{0}$ - площадь приемной апертуры телескопа, равная $0.13 \mathrm{~m}^{2} ; G(H)-$

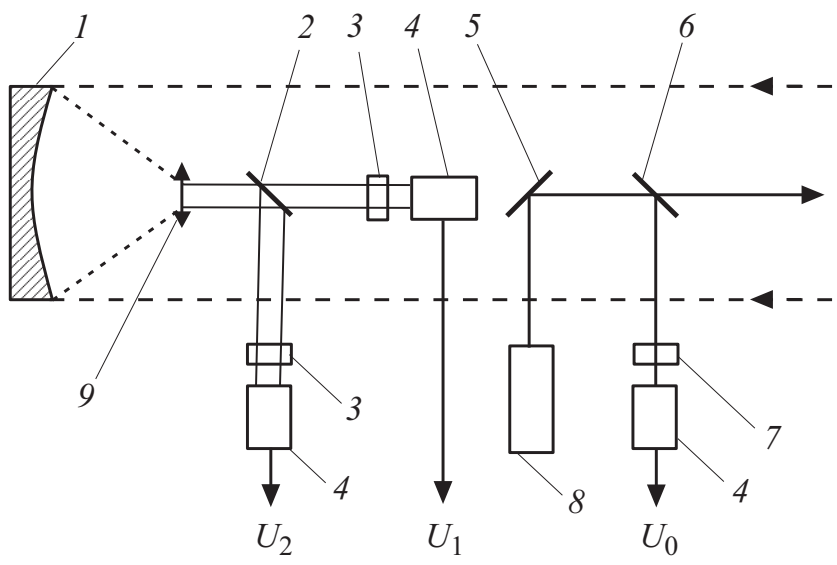

Pис. 2. Оптическая схема лидара комбинационного рассеяния света: 1 - сферическое зеркало приемного телескопа, 2 интерференционный светоделитель $618 / 630 \mathrm{~nm}, 3$ - интерференционные светофильтры, 4 - фотоприемники, 5 - глухое зеркало, 6 - стеклянная пластина, $7-$ светофильтр, 8 лазер, 9 - линзовый объектив.

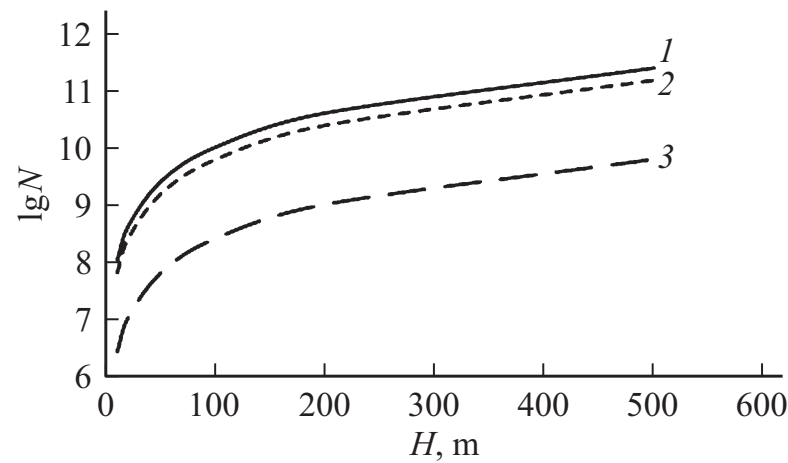

Рис. 3. Графики рассчитанной по уравнению (2) логарифмической зависимости зарегистрированной концентрации $N(H)$ $\left(\right.$ в $\left.\mathrm{cm}^{-3}\right)$ от расстояния зондирования $\mathrm{H}($ в $\mathrm{m})$ для полос антисимметричного валентного СН-колебания (1) и симметричного валентного СН-колебания (3) молекулы метана, полосы валентного SH-колебания (2) молекулы сероводорода и для длины волны лазерного излучения $532 \mathrm{~nm}$ при зондировании в атмосфере.

геометрическая функция лидара, $t$ - время измерения, $\alpha\left(\lambda_{0}, z\right)$ и $\alpha(\lambda, z)$ - коэффициенты ослабления на частотах лазерного излучения и комбинационного рассеяния света молекулами сероводорода и метана из таблицы. Для нашей экспериментальной ситуации возьмем время измерения $10 \mathrm{~s}$. Остальные обозначения те же, что и ранее.

Будем рассматривать однократное комбинационное рассеяние и однородную среду $[4,10]$. В качестве меры эффективности лидара возьмем значение минимальной концентрации, которое можно зарегистрировать на расстоянии зондирования $H$. Тогда из уравнения (1) выразим эту концентрацию исследуемых молекул в атмосферном воздухе в виде

$$
\begin{aligned}
N(H)= & n(\lambda, H) H^{2} /\left[n_{0} K_{1} \Delta H G(H) f t_{d} S_{0}\right. \\
& \times \exp \left[-\int_{0}^{H} \alpha\left(\lambda_{0}, z\right) d z-\int_{0}^{H} \alpha(\lambda, z) d z\right]\left(\frac{d \sigma}{d \Omega}\right] .
\end{aligned}
$$

Рассмотрим численное решение уравнения (2) в предположении, что $G(H)$ для нашего случая равно 1, время измерения $10 \mathrm{~s}$ и за это время измерения $t$ будут зарегистрированы 10 фотонов. Результаты решения уравнения (2) для этого случая представлены на рис. 3.

Как следует из графика рис. 3, спектральные зависимости величин, входящих в уравнение (2), дают минимальное значение концентрации на всех расстояниях зондирования для полосы симметричного валентного СН-колебания молекулы $\mathrm{CH}_{4}$ и возрастанию этого значения концентрации для полосы валентного $\mathrm{SH}$-колебания молекулы $\mathrm{H}_{2} \mathrm{~S}$ и затем - для полосы антисимметричного валентного СН-колебания молекулы 
$\mathrm{CH}_{4}$, причем на первых $100 \mathrm{~m}$ это значение растет в ряду $2.7 \cdot 10^{8}-6.7 \cdot 10^{9} \mathrm{~cm}^{-3}-1.1 \cdot 10^{10} \mathrm{~cm}^{-3}$ за время измерения $10 \mathrm{~s}$.

Причем за это время измерения на длине волны лазерного излучения $532 \mathrm{~nm}$ при частоте следования лазерных импульсов $1 \mathrm{MHz}$ и времени одного измерения $50 \mathrm{~ns}$ (шага по высоте $\Delta H=7.5 \mathrm{~m}$ ) такой вариант лидара комбинационного рассеяния света позволит зарегистрировать молекулы сероводорода с концентрацией, равной ПДК только до высоты $420 \mathrm{~m}$, а молекулы метана - на всех высотах Уменьшение концентрации молекул $\mathrm{H}_{2} \mathrm{~S}$ на больших расстояниях (до $500 \mathrm{~m}$ ) возможно за счет увеличения времени измерения до $12 \mathrm{~s}$ или увеличения частоты следования лазерных импульсов, или увеличения их энергии.

Рассмотрим зависимость минимальной концентрации исследуемых молекул от длины волны лазерного излучения для молекул сероводорода и метана.

Как следует из графиков рис. 4,5, спектральные зависимости величин, входящих в уравнение (2), приводят к увеличению минимально зарегистрированной концентрации $N(H)$ для молекулы $\mathrm{H}_{2} \mathrm{~S}$ в ряду длин волн лазерного излучения $405-532-655 \mathrm{~nm}$, а для молекулы $\mathrm{CH}_{4}$ в ряду длин волн лазерного излучения 532-405-655 nm.

Минимальное значение концентрации молекулы $\mathrm{H}_{2} \mathrm{~S}$ можно получить на длине волны $405 \mathrm{~nm}$ : для $50 \mathrm{~m}$ это значение составит почти $4.5 \cdot 10^{8} \mathrm{~cm}^{-3}$, для $100 \mathrm{~m}-$ $1.8 \cdot 10^{9} \mathrm{~cm}^{-3}$, а для $500 \mathrm{~m}-4.5 \cdot 10^{10} \mathrm{~cm}^{-3}$ при частоте следования лазерных импульсов $1 \mathrm{MGz}$ и времени одного измерения $50 \mathrm{~ns}$, что меньше ПДК. В то же время минимальное значение концентрации молекулы $\mathrm{CH}_{4}$ получается на длине волны $532 \mathrm{~nm}$ : для $50 \mathrm{~m}$ это значение составит почти $6.7 \cdot 10^{7} \mathrm{~cm}^{-3}$, для $100 \mathrm{~m}-2.7 \cdot 10^{8} \mathrm{~cm}^{-3}$, а для $500 \mathrm{~m}-6.7 \cdot 10^{9} \mathrm{~cm}^{-3}$ при зондировании по полосе симметричного валентного СН-колебания молекулы метана, что почти на шесть порядков меньше ПДК. Следовательно, время измерения для зондирования молекул метана по полосе симметричного валентного $\mathrm{CH}-$ колебания может быть уменьшено до десятков микросекунд, как и ранее в [4].

Для высот от 10 до $500 \mathrm{~m}$, на которых летают различные беспилотные летательные аппараты, время, необходимое для регистрации сигнала с концентрацией ПДК молекул сероводорода для длины волны $405 \mathrm{~nm}$, составит $10 \mathrm{~s}$. При этом за $10 \mathrm{~s}$ смещение летательного аппарата, движущегося со скоростью $10 \mathrm{~m} / \mathrm{s}$, составит $100 \mathrm{~m}$ и приведет к увеличению измерительного объема до почти $5000 \mathrm{~m}^{3}$ с высотой $500 \mathrm{~m}$, а на $7.5 \mathrm{~m}$ высоты придется около $667 \mathrm{~m}^{3}$. Движение летающей платформы приводит к заметному увеличению измерительного объема с $500 \mathrm{~m}^{3}$ до $5000 \mathrm{~m}^{3}$ или на порядок по сравнению с неподвижной платформой.

Таким образом, анализ полученных результатов показывает, что за время измерения $10 \mathrm{~s}$ при зондировании на длине волны лазерного излучения $405 \mathrm{~nm}$, высоты

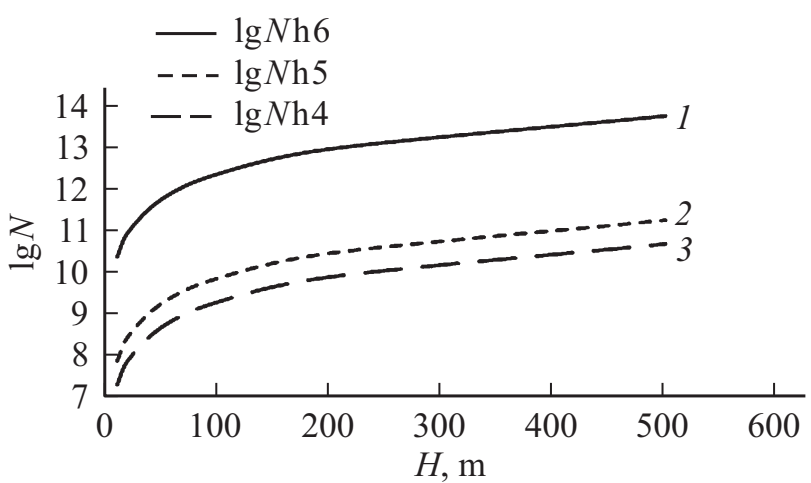

Рис. 4. Графики рассчитанной по уравнению (2) зависимости зарегистрированной концентрации $N(H)$ валентного SHколебания молекулы сероводорода для длин волн лазерного излучения 655 (1), 532 (2) и 405 (3) nm при зондировании в атмосфере.

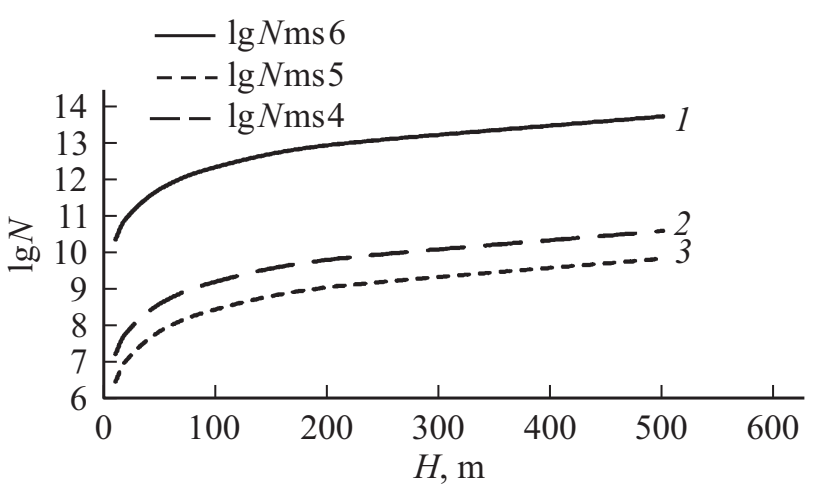

Рис. 5. Графики рассчитанной по уравнению (2) логарифмической зависимости зарегистрированной концентрации $N(H)$ $\left(\right.$ в $\mathrm{cm}^{-3}$ ) от расстояния зондирования $H$ (в $\left.\mathrm{m}\right)$ для полосы симметричного валентного СН-колебания молекулы метана для длин волн лазерного излучения 655 (1), 405 (2) и 532 (3) nm при зондировании в атмосфере.

полета платформы в диапазоне до $500 \mathrm{~m}$ может быть зарегистрирована концентрация исследуемых молекул сероводорода и метана ниже уровня ПДК для такого варианта лидара комбинационного рассеяния света. Поэтому можно вести речь о регистрации таким лидаром с летающей платформы за времена менее $10 \mathrm{~s} \mathrm{c} \mathrm{высоты}$ $100 \mathrm{~m}$ концентрации исследуемых молекул сероводорода ниже уровне ПДК.

Полученные результаты хорошо согласуются с данными [9] и отражают различие в уровнях ПДК исследованных молекул углеводородов [4], а разработка новых вариантов фотоприемников лидаров открывает потенциальные возможности для дистанционного зондирования концентраций молекул сероводорода и метана на уровне ПДК в атмосферном пограничном слое с летающей платформы. 


\section{Финансирование работы}

Работа была частично поддержана в рамках Основной части Гос. задания Министерства образования и науки РФ № 5.7721.2017/БЧ.

\section{Конфликт интересов}

Авторы заявляют, что у них нет конфликта интересов.

\section{Список литературы}

[1] Privalov V.E., Shemanin V.G. // Opt. Spectrosc. 2018. V. 125. N 4. P. 590-593. doi 10.1134/S0030400X18100181

[2] Иванов А. Из Черного моря уходит жизнь. $\mathrm{http} / / /$ svpressa.ru/society/article/155858/?cbt=1 06.09.2016.

[3] Шнюков Е.Ф., Старостенко В.И., Гожик П.Ф. // Геофиз. журн. 2001. № 4. С. 7-14.

[4] Привалов В.Е., Фотиади А.Э., Шеманин В.Г. Лазеры и экологический мониторинг атмосферы. СПб.: Лань, 2013. $288 \mathrm{c}$.

[5] Привалов В.Е., Шеманин В.Г. // ОПт. и спектр. 2017. T. 123. № 6. C. 941.

[6] Privalov V.E., Shemanin V.G. // Proc. SPIE. 1998. V. 3345. P. 6.

[7] Свердлов Л.М., Ковнер М.А., Крайнов Е.П. Колебательные спектры многоатомных молекул. М.: Наука, 1970. $562 \mathrm{c}$.

[8] Зуев В.Е., Макушкин Ю.С., Пономарев Ю.Н. Спектроскопия атмосферы. Л.: Гидрометеоиздат, 1987. 247 с.

[9] Межсерис Р. Лазерное дистанционное зондирование. М.: Мир, 1987. $550 \mathrm{c}$.

[10] Донченко В.А., Кабанов М.В., Кауль Б.В., Самохвалов И.В. Атмосферная электрооптика. Томск: Изд-во НТЛ, 2010. C. $178-181$. 